\title{
TEORIA DA TRADUÇÃO NA PRÁTICA \\ AS ARMADILHAS DA TRADUÇÃO \\ LE TRAPPOLE DELLA TRADUZIONE
}

Edvaldo Sampaio Belizário1 (UERJ)

\section{Resumo}

Traduzir não é um trabalho puramente mecânico que requer apenas um bom conhecimento de duas línguas (língua de partida e língua de chegada) e o auxílio de bons dicionários. Não basta substituir as palavras de uma frase, uma por uma, da língua de partida por seus equivalentes da língua de chegada. Traduzir é um ato muito mais complexo. As palavras não possuem sentido isoladamente, mas dentro do contexto na qual estão inseridas. Na verdade, as aplicações possíveis de qualquer palavra são inúmeras e imprevisíveis. Um vasto conhecimento vocabular de ambas as línguas não é suficiente para garantir a qualidade do texto traduzido. É necessário que o tradutor tenha um bom conhecimento da cultura dos povos que falam as línguas envolvidas no ato da tradução. Além disso, o tradutor precisa ter muita atenção para não cair nas inúmeras armadilhas que povoam o texto. Um bom trabalho de tradução requer muito conhecimento vocabular e cultural, perícia e bom senso do tradutor para não produzir textos equivocados ou de difícil compreensão para o leitor.

Palavras-chave: tradução-armadilha-palavra-língua-texto

\footnotetext{
${ }^{1}$ Professor Mestre. E-mail: edvambel@bol.com.br
} 


\section{Riassunto}

Tradurre non è un lavoro del tutto meccanico che richiede soltanto una buona conoscenza di due lingue (lingua di partenza e lingua di arrivo) e l'uso di appropriati dizionari. Non basta sostituire le parole di una frase della lingua di partenza con quelle equivalenti della lingua di arrivo. Tradurre è un atto molto più complesso di quanto si pensi. Le singole parole non hanno un senso isolatamente, ma dentro il contesto in cui sono inserite. In realtà, i significati di una parola sono innumerevoli ed imprevedibili. Una conoscenza lessicale ampia di ambedue le lingue non è sufficiente per la garanzia della qualità del testo tradotto. Occorre che il traduttore abbia un'ottima conoscenza della cultura dei popoli che parlano le rispettive lingue coinvolte nel processo della traduzione. Inoltre, chi fa la traduzione deve fare molta attenzione per non cascare nelle tantissime trappole contenute nel testo. Un eccellente lavoro di traduzione richiede molta conoscenza lessicale e culturale, destrezza e buonsenso del traduttore, altrimenti rischia di rendere il testo originale incomprensibile alla maggior parte dei lettori.

Parole chiave: traduzione-trappola-parola-lingua-testo

Talvez alguém possa imaginar que traduzir é uma prática puramente mecânica, que demanda apenas um bom conhecimento de duas línguas (a língua-fonte ou língua de partida e a língua-meta ou língua de chegada) e o auxílio de bons dicionários. Dessa forma, basta substituir as palavras de uma frase, uma por uma, por seus equivalentes na outra língua e pronto, está feita a tradução.

$\mathrm{Na}$ verdade, traduzir não é tão simples assim. As palavras não possuem sentido isoladamente, mas dentro de um contexto. Não podemos 
simplesmente dizer que uma palavra significa isto ou aquilo sem considerar o contexto no qual ela está inserida.

A palavra italiana davvero equivale a "deveras" e "realmente" em português. Porém se considerarmos seu uso dentro de um contexto, a mesma palavra pode ter um significado bem particular. No filme Parenti serpenti, de Mario Monicelli, o personagem Mauro, no desfecho da história, ao ler a sua redação na escola, revela: "Le mie vacanze sono cominciate bene, però sono finite male, perché sono morti tutti i due miei nonni". A professora interrompe o menino, expressando todo o seu espanto pela revelação feita, dizendo "davvero?". Nesse caso, tal expressão pode ser perfeitamente traduzida na nossa língua como "é mesmo?", acomodando muito bem o sentido de incredulidade do termo italiano que as palavras "deveras" e "realmente" não comportam.

$\mathrm{Na}$ verdade, as aplicações possíveis de qualquer palavra são inúmeras e imprevisíveis. Por isso, o trabalho do tradutor vai muito além do simples fato de pegar palavras e dar a elas meros significados. Um excelente conhecimento vocabular não garante o primor do trabalho do tradutor. Ao excelente conhecimento vocabular se deve acrescentar um não menos primoroso conhecimento da cultura de cada língua envolvida no ato da tradução.

A prática da tradução é, sem dúvida, uma importante ferramenta para a difusão das diversas culturas além dos limites de suas fronteiras geográficas. Lembremo-nos que, em latim, traducere é fazer passar de um ponto para outro, transferir, atravessar. Portanto, o termo "traduzir" pode ser compreendido como condurir um texto escrito numa lingua para o dominio de outra diferente. Como pode ser feita essa "condução"? Paolo Rónai nos apresenta duas variantes extremas:

Conduzir uma obra estrangeira para outro ambiente linguístico significa querer adaptá-la ao máximo aos costumes do novo meio, retirar-lhe as características exóticas, fazer esquecer que reflete uma realidade longínqua, essencialmente diversa. Conduzir o leitor para o país da obra que lê significa, ao contrário, manter cuidadosamente o que essa tem de estranho, de genuíno, e acentuar a cada instante a sua origem alienígena. (RÓNAI, 1981, p.20) 
Seguindo uma variante ou outra, o trabalho do tradutor requer muito conhecimento linguístico e cultural de ambas as línguas envolvidas na tradução, muita técnica e bom senso para não se produzirem textos equivocados ou de difícil compreensão para o leitor. É digno de nota, também, manter-se sempre atualizado na língua de sua especialização, não deixando jamais de estudá-la, lê-la, falá-la, escrevê-la e ouvi-la. Aconselha-se, também, ao tradutor, reler a página que acaba de verter, pois, dessa forma, ele pode descobrir enunciados não pertinentes à sua língua. Além disso, o tradutor perspicaz deve estar atento às armadilhas da tradução.

\section{As Armadilhas da Tradução}

O trabalho do tradutor, diz Paulo Rónai, "passa por um caminho ladeado de armadilhas" (RÓNAI, 1981, p.34). Certamente, até os melhores profissionais da tradução já passaram por algum contrassenso durante o seu trabalho. São inúmeras as causas de tais enganos. Nesse trabalho apontaremos os casos mais comuns de armadilhas da tradução, característicos dos textos traduzidos do italiano para o português e vice-versa.

\section{1) Textos literários}

Os textos literários são, de fato, um problema a mais para o tradutor, pois o obriga a utilizar os seus conhecimentos de técnico para conseguir efeitos de arte e provocar emoções estéticas que o texto de partida apresenta. Quando se trata de tradução poética, o trabalho do tradutor aumenta consideravelmente e a sua atenção deve ser redobrada. A escolha das palavras deve seguir um critério estritamente estético e peculiar. A métrica, a rima, o ritmo, a sonoridade, a colocação das palavras, a harmonia das estrofes, todas 
essas características de um texto poético devem ser preservados pelo tradutor quando ele recria o poema em seu idioma.

No caso da tradução poética, dificilmente a versão será literal, pois seria um trabalho cuja realização se tornaria quase impossível. É importante que o tradutor tenha um conhecimento muito amplo da sua língua para poder fazer uso de todas as possibilidades que essa lhe oferece.

Muitas vezes, o tradutor deve recorrer a um termo que mantenha o sentido semântico da palavra do outro idioma para obter uma rima ou manter a métrica inviolada. Outras vezes, é necessário que se troque a posição de uma ou outra palavra em relação ao verso do original para se resguardar toda a sua estrutura poética. Na tradução do poema Il girotondo della settimana, de Piera Stefani, feita numa sala de aula, podemos ver a utilização desses recursos:

\author{
Lunedì ha un lavoro da fare; \\ Martedì non lo vuole aiutare; \\ Mercoledì si vuol divertire; \\ Giovedì preferisce dormire. \\ Venerdì pensa: - È tardi, ahimè! \\ Sabato dice: - Non contate su me. \\ Domenica: - Io riposo tutto il dì. \\ E Il lavoro resta li, \\ Poi ritorna... il Lunedì!
}

Vejamo-lo na versão em português:

Segunda tem um trabalho para realizar;

Terça não quer ajudar;

Quarta quer se divertir;

Quinta prefere dormir.

Sexta pensa: - É tarde, que castigo!

Sábado diz: - Não contem comigo.

Domingo: - Eu descanso a jornada inteira.

Fica ali toda a trabalheira,

Volta, então... a Segunda-feira! 
Podemos reparar que os dias da semana não vêm acompanhados da palavra "feira" para que seja conferida aos protagonistas do poema a informalidade que o texto requer, com exceção da segunda recorrência do dia segunda-feira, pois ali o segundo termo, que compõe o nome, é essencial para a sequência de rimas. A interjeição abimè (em português, "ai de mim”) é vertida pelo termo interjecional "que castigo" por exigência da rima com o verso subsequente. A sequência de rimas dos versos finais é obtida com o adjetivo "inteira" e o substantivo "trabalheira", posicionados de modo diferente do texto original.

É lógico que se trata de um poema moderno que não tem o rigor métrico das poesias antigas. Entretanto, é bom salientarmos a necessidade de se observarem todas as características da tradução poética para que o efeito produzido no original seja preservado na tradução, seja ele um poema antigo ou moderno. Dessa forma, podemos fazer com que o leitor tenha o mesmo prazer da contemplação que a obra poética oferece no seu texto original.

\section{2) Aspectos culturais, etimológicos e gramaticais}

Algumas palavras de duas línguas podem ter o mesmo significado, ou seja, podem ser definidas de maneira igual, mas as conotações que evocam podem ser diferentes em alguns casos. A palavra italiana appello pode ter o mesmo sentido em português quando significa "apelo", "solicitação", mas somente em italiano designa "a lista de chamada dos alunos".

Em outros casos, podemos encontrar palavras que, embora não tenham semelhança morfológica com aquela equivalente na outra língua, possuem uma designação bem precisa, embora sua aplicação passe por critérios bem específicos. A palavra italiana benzinaio significa em português "frentista", porém o seu uso em italiano respeita critérios que só podem ser considerados nessa língua. A frase "vado dal benz̧inaio" teria uma tradução que causaria estranheza em português se considerarmos o seu sentido literal "vou ao 
frentista", mas a tradução "vou ao posto de gasolina" retoma o aspecto sóbrio da frase. Como podemos notar, a palavra italiana benzinaio tem um significado bem preciso em português, isto é, "frentista", porém o seu uso prático passa por um critério que é muito peculiar ao falante italiano.

O uso abundante do gerúndio na nossa língua, não muito cultuado na língua italiana e no português de Portugal, pode causar alguns embaraços para o tradutor descuidado. A sequência de frases Paulo, vem aquil; estou indo pode colocar o tradutor em apuros se traduzida para o italiano como Paolo, vieni quil; sto venendo, pois stare venendo na gíria italiana quer dizer estar tendo um orgasmo. Nesse caso, no lugar da expressão embaraçosa, se poderia colocar, sem prejuízo para a tradução, os verbos venire ou arrivare no presente do indicativo, ou seja, vengo ou arrivo, pois as duas formas acomodariam perfeitamente a nossa expressão estou indo.

Um problema de ambiguidade poderia nascer para um leitor italiano se a frase a mãe viu o filho chorando no quintal fosse traduzida la mamma ha visto il figlio piangendo in cortile, pois o gerúndio em italiano é usado de praxe em referência ao sujeito da frase e não ao seu objeto. Assim, em italiano a mãe chorava e não o filho. A informação contida na frase em português, na qual a ação de chorar é feita pelo menino, não traria nenhuma ambiguidade em italiano se o verbo piangere viesse no imperfeito do indicativo em vez de ser expresso no gerúndio. Assim, a frase la mamma ha visto il figlio che piangeva in cortile não comportaria nenhuma ambiguidade para o leitor italiano.

Um outro caso que envolve um tempo verbal é o uso do "futuro semplice" em italiano para as frases no período hipotético. Para esse tipo de enunciado, temos em português um tempo verbal bem específico, isto é, o "futuro do subjuntivo simples". Entretanto, para o tradutor desatento, esse detalhe pode virar uma armadilha e a tradução de uma singela frase como se aurò tempo, andrò in chiesa pode sair como se terei tempo, irei à igreja. Como 
podemos observar, o verbo "ter" foi traduzido no futuro do presente do indicativo (terei) quando deveria vir no futuro do subjuntivo simples (tiver).

Muitas vezes, o tradutor ao verter um texto para a sua língua faz uso inconsciente da regência verbal da outra língua. Tal prática pode levar o tradutor a cometer equívocos no seu trabalho, mesmo em se tratando de línguas bem parecidas. A regência verbal é o "DNA" de uma língua. Ela nunca será completamente igual em idiomas diferentes. Não é raro encontrar textos traduzidos do italiano para o português contendo frases em que a regência do verbo não obedece às normas cultas da nossa língua. Eis aqui alguns dos exemplos mais frequentes nos quais a regência da língua italiana prevalece também na versão em português: io tento di essere um buon alunno $=e u$ tento de ser um bom aluno, penso di fare um viaggio all'estero = penso de fazer uma viagem ao exterior, lui si preoccupa per la salute di sua madre = ele se preocupa pela saúde de sua mãe, l'accusa si basa sulle testimonianze = a acusação se baseia sobre os testemunhos.

Por todos esses motivos, recomenda-se ao tradutor sempre verificar as páginas traduzidas para que ele possa observar as possíveis anomalias do texto e, dessa forma, prosseguir com as correções.

\section{3) Palavras polissêmicas}

Outro perigo para o tradutor são as palavras polissêmicas, ou seja, aquelas que possuem uma multiplicidade de significados. Um tradutor deve estar sempre atento ao contexto para não incorrer em erros de tradução, sobretudo quando se depara com essas palavras. Existem muitos desses casos tanto no português quanto no italiano. A palavra italiana "piano", por exemplo, tem uma gama de significação que a nossa língua não possui. Nas seguintes frases podemos observar os seus diversos significados: "terreno piano" (terreno plano), "parlare in modo piano" (falar de modo claro), "mangiare piano" (comer devagar), "piano di lavoro" (projeto de trabalho), 
"suonare il piano" (tocar o piano) e "abitare al terzo piano" (morar no terceiro andar).

O verbo italiano cacciare é outro exemplo interessante de termo polissêmico. Dependendo do contexto no qual o verbo vem inserido, pode significar "caçar", "expulsar", "tirar”, "soltar”, “colocar", "enfiar”. A sua curiosa significação antitética de "tirar" e "colocar" justifica o termo cacciavite que em italiano significa "chave de fenda", pois o conhecido utensílio tem a dupla função de colocar e tirar parafusos.

Naturalmente, os bons dicionários registram todas as acepções de um vocábulo e os seus diversos significados na outra língua, mas o tradutor deve ser zeloso para não se equivocar quanto ao uso dessas palavras.

\section{4) Os cognatos aparentes ou falsos amigos}

As palavras semelhantes em duas línguas, mas de sentidos totalmente diversos, isto é, os cognatos aparentes ou falsos amigos, representam um verdadeiro perigo para o tradutor. A língua italiana é repleta de falsos amigos em relação ao português, sobretudo por se tratar de uma língua que tem a mesma origem da nossa. Um leve descuido do tradutor pode levá-lo a traduzir seta por "seta" em vez de "seda"; caldo por "caldo" ao invés de "quente"; prego por "prego" no lugar de "de nada"; soprannome por "sobrenome" em vez de "apelido".

Algumas vezes os falsos amigos podem provocar verdadeiras confusões ao texto quando traduzidos de forma negligente. Andare in galera em língua italiana não é tão interessante como o nosso "ir para a galera", pois significa "ir para a prisão"; bere un vino squisito em italiano é muito mais aprazível do que "beber um vinho esquisito" na nossa língua, uma vez que quer dizer "beber um vinho delicioso"; o uso da expressão una ragazza deliziosa em italiano, não causa o constrangimento que, no Brasil, certamente, ocorreria, visto que a palavra deliriosa, nesse contexto, significa "encantadora" e não "gostosa". 


\section{5) As palavras homônimas e parônimas}

As palavras homônimas são aquelas que apresentam grafia e/ou pronúncia idênticas. Entre as palavras homônimas podemos lembrar accètta (aceita - verbo) e accétta (machado); compito (tarefa) e compito (realizado - part. pass. compiere); vita (vida) e vita (cintura).

Não menos perigosas são as palavras parônimas que requerem a mesma atenção por parte do tradutor. Tão vasto quanto o grupo das palavras homônimas é o das palavras parônimas. Em português temos os pares "descrição" e "discrição", "seção" e "sessão", "infligir" e "infringir", "ratificar" e "retificar", "absolver" e "absorver"; em italiano, por sua vez, temos scrivere e iscrivere, mento e menta, cedere e cadere.

Especificamente, no caso da língua italiana, podemos acrescentar a esse grupo as "doppie" (palavras que dobram as consoantes). Então, muito cuidado na hora de se traduzir $i$ pani (os pães) e $i$ panni (os panos); il capello (o cabelo) e il cappello (o chapéu); la penna (a caneta) e la pena (o castigo); sono (são - verbo) e sonno (sono); tutta (toda) e tuta (macacão).

Ambos os grupos representam perigo para o tradutor, pois a confusão já pode partir do texto original. Por esse motivo, a atenção do tradutor deve ser dobrada ao se deparar com essas palavras.

\section{6) Os sinônimos}

Os sinônimos, palavras de sentido idêntico ou semelhante, representam outro tipo de emboscada. O tradutor precisa ponderar para o uso da palavra adequada quando há dois ou mais sinônimos para ela. Às vezes, nem sempre uma das opções é de uso frequente ou adequado para certas situações na língua de chegada. Por isso, o vocábulo italiano trappola pode ter dois equivalentes em português, "trápola" e "armadilha". No português utilizado 
no Brasil, a palavra "trápola", embora seja sinônimo de "armadilha”, não é usual. O mesmo se aplica à palavra italiana scopo, que seria melhor traduzida para a nossa língua como "objetivo" em vez de "escopo". Em português, por exemplo, as palavras "pai" e "papai" são sinônimas, mas na frase "fulano de tal, papai de três filhos" a palavra "papai" não substitui "pai”.

Para o caso dos sinônimos, o bom tradutor deve saber interpretar o sentido de um vocábulo para melhor transportá-lo em sua língua, observando as necessidades e as particularidades que envolvem o uso de um sinônimo ou outro em um determinado contexto.

\section{7) Palavras que designam noções peculiares a uma civilização}

Algumas palavras são peculiares a uma determinada civilização e não

têm equivalentes nos demais ambientes culturais. É o caso, por exemplo, da palavra italiana mafia e da palavra do português do Brasil "samba". Palavras como essas devem conservar o seu formado original nos diversos textos. Os casos mais frequentes são os das palavras de uso exclusivamente regional nos diferentes ambientes culturais, como, por exemplo, as palavras "sertão" e “jangada”. O melhor a se fazer, nesses casos, é conservar o vocábulo na sua forma original e colocar uma nota, explicando o seu significado.

\section{8) Os nomes próprios}

Os antropônimos, ou nomes próprios de pessoas, são palavras destituídas de significação, mas possuem um valor conotativo dos mais fortes. Não existe regra geral sobre a tradução dos antropônimos. Na língua italiana é comum a naturalização dessas palavras, sobretudo quando para elas há uma equivalente. Não é raro encontrar em um dicionário enciclopédico italiano Beniamino Franklin (Benjamin Franklin), Adolfo Hitler (Adolf Hitler), Isacco 
Newton (Isaac Newton), Carlo Marx (Karl Marx). No Brasil os antropônimos são geralmente mantidos em suas formas primitivas, mas o Napoléon ou Napoleone Bonaparte será sempre conhecido como Napoleão Bonaparte.

Quanto aos nomes das personagens de obras literárias, é preciso que o tradutor tenha bom senso na hora de decidir sobre traduzi-los ou não. É preferível que os nomes sejam mantidos na sua forma primitiva, mas, em alguns casos, convém que seja feita a conversão para a língua em que o texto está sendo traduzido, principalmente quando os nomes originais possuem um equivalente na outra língua, viabilizando até mesmo a pronúncia de nomes de difícil grafia. Ficamos muito mais à vontade com Guilherme Tell do que com Wilhelm Tell, por exemplo. Por outro lado, parece-me desagradável ler os nomes traduzidos de algumas personagens do I promessi sposi, de Alessandro Manzoni, em certas traduções que circulam na nossa língua, no lugar das suas formas primitivas. Ao lermos Lúcia ou Luzia e Inês, no lugar de Lucia e Agnese, por exemplo, nos dá a impressão de se tratar de uma outra obra. Até mesmo com os nomes que são dotados de significação especial é aconselhável que sejam mantidos na sua forma original, podendo-se esclarecer o sentido numa nota de pé de página. É o caso do nome do advogado Azzecca-garbugli, do romance manzoniano, para o qual cabe um nota de pé de página explicando a sua significação especial através dos adjetivos “enganador" e "enrolão".

É preferível, também, não traduzir os hipocorísticos ou nomes que denotam carinho, tais come Beppe (variante de Giuseppe), Gigio (variante de Luigi), Tony (variante de Antonio). Todavia, nomes próprios usados metaforicamente como nomes comuns devem ser vertidos, como, por exemplo, Tizio, Caio e Sempronio, em português, Fulano e Sicrano.

Os topônimos, ou nomes geográficos, devem ser traduzidos somente quando na outra língua exista um equivalente. Firenz̧e (Florença), Venez̧ia (Veneza), Napoli (Nápoles), Torino (Turim), Monaco di Baviera (Munique), são 
nomes perfeitamente traduzíveis, mas "Fiume di Gennaio" por Rio de Janeiro em italiano seria certamente uma aberração, bem como "Três Caras" por Treviso em português.

\section{9) Expressões idiomáticas}

As expressões idiomáticas são as verdadeiras "armadilhas" da tradução. Elas podem tornar temerária a operação do tradutor, sobretudo quando há falta de expressões equivalentes na outra língua. São inúmeras as expressões idiomáticas e os seus significados têm um valor muito particular em cada idioma. Nesse caso, a tradução deve ser feita pelo sentido da expressão e jamais pelo seu significado literal. "Quebrar um galho" em português não pode ser traduzido para o italiano como spezzare un fuscello, nem mesmo prendere in giro em português seria "pegar em giro", pois cada uma dessas expressões carrega nos seus respectivos idiomas uma significação muito inerente às suas diversas culturas, ao seu modo de olhar e descrever as suas emoções e experiências.

É bem verdade que, em alguns casos, podemos encontrar uma expressão idiomática que é reproduzida de uma forma muito semelhante no outro idioma, como por exemplo, "non scherzare col fuoco" em italiano e "não brinca com fogo" em português. Seria muito mais fácil para a prática de tradução, se todas as expressões idiomáticas tivessem uma equivalência em ambas as línguas, mas, infelizmente, a realidade é outra, levando o trabalho do tradutor para um campo deveras perigoso. É nessa hora que o tradutor tem que ser, de fato, um tradutor.

Em alguns casos particulares, as expressões idiomáticas são reforçadas por termos que delas participam, perdendo o seu significado próprio, ainda que sejam unívocos. É o caso do numeral "quatro" que em língua italiana tem 
um uso muito particular, como podemos observar nos exemplos que seguem: fare quattro chiacchiere (bater um papo), fare quattro passi (dar uma voltinha) e colloquio a quattrocchi (conversa em particular).

As expressões idiomáticas são a confirmação que não se traduz palavras, mas sentenças. No caso particular das expressões idiomáticas, o tradutor deve procurar na sua língua as palavras exatas que melhor expressariam a ideia contida no enunciado do texto original.

\section{0) Provérbios}

Por sintetizarem um conceito a respeito da realidade ou uma regra social e moral, ricas de imagens, ritmo e rimas, muitas vezes, os provérbios devem ter uma tradução que contenha o seu sentido moralizador. Na verdade, não há tradução de provérbios. O que existe, de fato, é a versão através de um provérbio que carregue consigo o mesmo sentido moralizador contido no da outra língua. Embora haja provérbios que têm equivalentes muito semelhantes, não podemos jamais fazer uma tradução literal do seu enunciado. $\mathrm{O}$ provérbio italiano tra moglie e marito non mettere il dito, cujo equivalente em português é "em briga de marido e mulher não mete a colher", tem uma estrutura muito similar a nossa. A única diferença entre os dois provérbios está no uso do substantivo que encerra os dois pensamentos por causa da rima. Entretanto, o caráter moralizador é o mesmo em ambas as línguas. Algumas vezes, é possível traduzir literalmente o provérbio, como, por exemplo, in bocca chiusa non entrano mosche por "em boca fechada não entram moscas", porque as palavras que compõem o provérbio em ambas as línguas são equivalentes. $\mathrm{Na}$ verdade, no momento de se traduzir um provérbio, deve-se encontrar um modelo equivalente na outra língua, independentemente das palavras que formam a máxima, observando, sobretudo, se o aspecto moralizador é o mesmo. 


\section{Considerações Finais}

O trabalho do tradutor vai muito além do simples fato de se ter em mãos alguns dicionários e de se converter palavra por palavra para outra língua. A tradução é uma arte que requer do tradutor muito conhecimento, muito preparo e, sobretudo, bom senso para dar ao seu trabalho sobriedade e elegância. Falamos muito na necessidade de se considerar o significado das palavras sempre relacionado ao contexto no qual cada uma delas está inserida. Falamos e reafirmamos aqui essa incontestável consideração. Por isso, foi de nossa total preocupação apontar as principais armadilhas que podem aparecer em um texto a ser traduzido. A esse respeito, portanto, ficou bastante claro que o objeto de nossas considerações foi a necessidade imprescindível de se tratar a tradução como um trabalho no qual o texto como um todo tem muito mais valor do que a mera conversão do vocábulo a partir da sua significação individual. Em outros termos, falamos de um trabalho no qual a consideração semântico-sintática deve prevalecer sobre o aspecto morfológico.

Poderíamos ter trazido à discussão outros aspectos menores sobre as armadilhas da tradução, porém julgamos desnecessário tal esforço, pois sabíamos que nossas conclusões a esse respeito não seguiriam veredas contrárias àquelas que foram apontadas nos temas considerados. Portanto, aconselhamos àqueles que querem fazer da tradução um meio de vida a considerarem cada ponto tratado no presente trabalho para que o trocadilho "tradutor traidor" nunca lhes sirva de referência.

\section{Referências Bibliográficas}

ALVES, Fabio; MAGALHÃES, Célia; PAGANO, Adriana. Tradurir com autonomia - estratégias para o tradutor em formação. 3 ed, São Paulo: Contexto, 2006. 
ARROJO, Rosemary. Oficina de tradução - A teoria na prática. 5 ed. São Paulo: Ática, 2007.

AUBERT, Francis Henrik. As (In)Fidelidades da Traducão - Servidões e Autonomia do tradutor. 2 ed. Campinas: Editora da Unicamp, 1994.

CAMPOS, Geir. Como fažer tradução. Petrópolis: Vozes, 1987.

O que é tradução. $1^{a}$ reimpressão da 2 ed. de 1987. São Paulo:

Brasiliense, 2004.

ECO, Umberto. Quase a mesma coisa. Rio de Janeiro: Record, 2007.

- Riflessioni Teorico-Pratiche sulla Traduzione in Teorie

Contemporanee della Tradurione, a cura di Siri Nergaard, Milano: Strumenti Bompiani, 1995.

FRANCISCO, Reginaldo; ZAVAGLIA, Claudia. Parece mas não é: as armadilhas da tradução do italiano para o português. São Carlos: Editora Claraluz, 2008.

IL SABATINI COLETTI - Dizionario della lingua italiana. Milano: Rizzoli Larousse, 2005.

MOUNIN, Georges. Teoria e storia della Tradurione. Torino: Giulio Einaudi editore s.p.a., 2006.

RÓNAI, Paulo. A Tradução Vivida. $2^{\mathrm{a}}$ ed. Rio de Janeiro: Nova Fronteira, 1981.

Escola de Tradutores. $5^{a}$ ed. Rio de Janeiro: Nova Fronteira, 1987.

SILVEIRA, Brenno. A Arte de Tradurir. $2^{a}$ ed. São Paulo: Melhoramentos Editora UNESP, 2004. 